reste ainsi difficile. Une voie est cependant ouverte dans cette direction par l'analyse de divers caractères génétiques liés à la drépanocytose, la proportion d'hémoglobine fœtale et l'existence d'une thalassémie associée par exemple.

D.L.

1. Pagnier J, Mears JG, Dunda-Belkhodja O at al. Evidence for the multicentric origin of the sickle cell hemoglobin gene in Africa. Proc Natl Acad Sci USA 1984; 81: 1771-3.

2. Miller BA, Salameh $M$, Ahmed $M$, et al. High fetal hemoglobin production in sickle cel anemia in the Eastern province of Saudi Arabia is genetically determined. Blood $1986 ; 67$ : 1404-10.

3. Kulozik AE, Wainscoat JS, Serjeant GR, at al. Geographical survey of $\beta^{\mathrm{S}}$-globin gene haplotypes : evidence for an independent asian origin of the sickle-cell mutation. Am J Hum Genet 1986 : 39 : 239-44.

4. Nagel RL, Fabry ME, Pagnier J, et al. Hematologically and genetically distinct forms of sickle cell anemia in Africa. The Senegal type and the Benin type. $N$ Engl J Med 1985 ; 312 : 880-4.

BRÈVES

- L'anti-oncogène dont la délétion homozygote est responsable du rétinoblastome et de l'ostéosarcome a peut-être été cloné. Le gène est localisé au niveau de la bande q14 du chromosome 13 et code pour un ARNm de $4,7 \mathrm{~kb}$ qui est présent dans les tissus normaux et absent dans des rétinoblastomes et ostéosarcomes. Des expériences ultérieures de transfection de cellules de rétinoblastome et d'ostéosarcome en culture avec l'ADNc ainsi cloné sous le contrôle d'un promoteur fort permettront de déterminer si le clone isolé code en effet pour un produit à effet antiprolifératif, faisant perdre aux cellules malignes en culture leur tumorigénicité.

[Friend SH et al. Nature 1986 ; 323 : 643-6.]

ERRATUM : Dans la nouvelle du $n^{\circ} 10$, vol. "Les $G$ protéines, un système universel de transduction des signaux $n$, il fallait lire, page 584 , à la $4^{\text {e }}$ ligne de la légende de la figure 2 : phosphodiestérase spécifique du GMP cyclique et non pas: phosphodiestérase stimulie par le GMP cyclique et détruisant l'AMPc.

$\mathrm{m} / \mathrm{s} n^{\circ} 1$ vol. 3 , janvier 87

\title{
L'agent de l'hépatite D est un virus ressemblant aux viroïdes des plantes
}

Comme il était prévisible à la suite du récent isolement d'un fragment de l'ADN complémentaire du génome du virus de l'hépatite $D$ (VHD) $(\mathrm{m} / \mathrm{s}$ $\mathrm{n}^{\circ} 2$, vol. 2, p. 409), c'est maintenant la structure complète de ce génome qui vient d'être élucidée $[1,2]$. Il s'agit d'un ARN circulaire monobrin de 1678 bases dont un brin complémentaire peut notamment coder pour une protéine de 215 acides animés qui est reconnue par les anticorps des malades porteurs du virus.

Les caractéristiques du génome viral sont ici très extraordinaires pour un système animal et se rapprochent étrangement de celles des viroides des plantes. Ces derniers sont en effet des molécules circulaires d'ARN monobrin très riche en GC (ce qui est le cas du génome VHD), dépourvues de capside virale (tout comme VHD qui emprunte la capside du virus associé de l'hépatite $B)$ et responsables de diverses maladies des végétaux infectés. De plus, quelques homologies de séquence existent entre l'ARN de VHD et celui de certains viroides végétaux.

Comme il est indiqué plus haut, le potentiel codant du virus ne semble pas porté par son ARN génomique, mais par un brin complémentaire (" antigénomique "); VHD serait donc un virus dont le génome serait constitué d'un brin négatif devant être repliqué en brin positif avant d'être traduit en protéines. Outre son grand intérêt pour l'étude des mécanismes de pathogénicité $d u$ virus $D$, la découverte des particu- larités de son génome établit un lien entre les mondes végétaux et animaux, qui pourrait donner des indications nouvelles sur l'évolution des espèces et sur les possibilités d'échanges de matériel génétique entre plantes et animaux.

Une autre hypothèse est cependant possible : le génome VHD et les viroides végétaux présentent de nombreuses homologies avec l'ARN de certains introns dits de type I, trouvés dans les précurseurs des messagers et des ARN ribosomaux de mitochondries de la levure et d'autres eucaryotes primitifs, des $A R N$ de transfert de chloroplastes de plantes, et des $A R N$ ribosomaux nucléaires de protozoaires. Le mécanisme d'excision de ces introns est, au moins en partie, autocatalytique et implique leur cyclisation $\left(\mathrm{m} / \mathrm{s} \mathrm{n}^{\circ} 5\right.$, vol. 2, p. 280). Viroïdes et virus de l'hépatite $D$ pourraient donc dériver de semblables introns possédant une origine de réplication leur permettant de se comporter comme des éléments génétiques autonomes. Les similitudes observées entre ces agents refléteraient alors l'hypothétique origine commune des introns de type I dont ils dériveraient.

A.K.

1. Wrang KS, Choo QL, Weiner A et al. Structure, sequence and expression of the hepatitis delta viral genome. Nature 1986 ; 323 : $558-60$.

2. Kos A, Dijkema R, Amberg AC, Van der Meide PH, Schellekens $H$. The hepatitis delta virus possesses a circular RNA. Nature 1986 $323: 508-50$
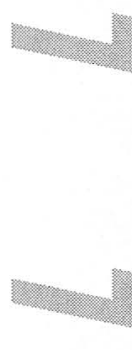

西 